\title{
Reinstatement of fear to an extinguished conditioned context
}

\author{
RICK RICHARDSON, TANIA Q. DUFFIELD, GLYNIS K. BAILEY, and R. FREDERICK WESTBROOK \\ University of New South Wales, Sydney, New South Wales, Australia
}

\begin{abstract}
Rats were shocked in the black but not the white compartment of a shuttlebox and then exposed to the black compartment in the absence of the shock unconditioned stimulus (US) to extinguish fear responses (passive avoidance). In five experiments, rats were then shocked in a reinstatement context (distinctively different from the shuttlebox) to determine the conditions that reinstate extinguished fear responding to the black compartment. Rats shocked immediately upon exposure to the reinstatement chamber failed to show either reinstatement of avoidance of the black compartment or fear responses (freezing) when tested in the reinstatement chamber. In contrast, rats shocked $30 \mathrm{sec}$ after exposure to the reinstatement chamber exhibited both reinstatement of avoidance of the black compartment and freezing responses in the reinstatement chamber (Experiment 1). Rats shocked after 30 sec of exposure to the reinstatement chamber but then exposed to that chamber in the absence of shock failed to exhibit reinstatement of the avoidance response and did not freeze when tested in the reinstatement chamber (Experiment 2). Rats exposed to a signaled shock in the reinstatement chamber and then exposed to that chamber in the absence of shock also failed to exhibit reinstatement of the avoidance response (Experiment 5). These rats showed fear responses to the signal but not to the reinstatement chamber. Finally, rats exposed for some time $(20 \mathrm{~min})$ to the reinstatement chamber before shock exhibited reinstatement of the avoidance response but failed to freeze when tested in the reinstatement chamber (Experiments 3 and 4). These results are discussed in terms of the contextual conditioning (Bouton, 1994) and the US representation (Rescorla, 1979) accounts of postextinction reinstatement.
\end{abstract}

The performance used to infer the formation of an excitatory association between two events [e.g., a conditioned stimulus (CS) and an unconditioned stimulus (US)] is reduced or lost when the CS is repeatedly presented in the absence of its associated US. Therefore, it has been assumed that this loss of performance to an extinguished CS indexes the destruction of the original excitatory association (e.g., Rescorla \& Wagner, 1972). However, various techniques have been used to show that extinction does not erase an excitatory CS-US association. For example, performance to an extinguished CS can be partly restored when it is presented either outside the context in which extinction occurred (renewal) or after a long retention interval (spontaneous recovery; see Bouton, 1994, for review). One explanation of these instances of response restoration is that extinction masks the excitatory association by establishing an inhibitory CS-US association (Pavlov, 1927). This inhibitory association is held to be specific to the extinction context, whereas the excitatory association is expressed in performance independent of the context in which it was established. Accordingly, renewal occurs because presentation of the CS outside the extinction context enables that CS to excite the US repre-

This research was supported by grants from the Australian Research Council. Correspondence should be addressed to R. Richardson, School of Psychology, University of New South Wales, Sydney NSW 2052, Australia (e-mail: rrichardson@unsw.edu.au). sentation in the absence of opposition from the contextually controlled inhibitory association (Bouton \& Ricker, 1994). Spontaneous recovery occurs through the same mechanisms except that here the context shift is produced by changes that have occurred within the organism across the long retention interval (Bouton, 1994). In these instances, restoration of performance to an extinguished CS is a consequence of the removal of its contextually controlled inhibitory association with the US.

Another technique that restores performance to an extinguished CS involves presentations of the US in the absence of its associated CS. Rescorla and Heth (1975) confirmed earlier reports of this effect (e.g., Konorski, 1948; Pavlov, 1927). They also reported that US presentations produced reinstatement whether or not the US had been signaled by another CS, or when some time ( $24 \mathrm{~h})$ had elapsed between the US presentations and the test for responding to the extinguished CS. Rescorla (1979) argued that this instance of response restoration to an extinguished CS was not due to the unmasking of the excitatory association via the action of the US presentations upon the inhibitory CS-US association. Rather, reinstatement of responding to an extinguished CS by US presentations results from a restoration of the US representation that has been depressed across extinction. This depression is experientially mediated but nonassociative in nature: It occurs because of the discrepancy between the nonoccurrence of the US and the repeated CS activation of its representation across extinction. According to this event 
memory model, some of the loss in performance under extinction is due to the excitation by the CS of a depressed US representation, and the reinstatement of that performance by US presentations is due to the restoration of that representation (Rescorla, 1979).

Several findings (e.g., Bouton \& Bolles, 1985; Bouton \& King, 1983; see Bouton, 1988, 1991, for reviews) led Bouton to reject this event memory model and to propose as an alternative that US presentations condition contextual stimuli, which then trigger performance to the extinguished CS. This triggering does not just represent the summation of the excitatory value of the context and that still residing in the extinguished CS. Rather, performance is triggered because the animal remembers the CS-US memory rather than the CS-no US memory in that context. It remembers the CS-US memory because the conditioned context constitutes a return to the circumstances (of background or contextual conditioning) under which that memory was originally formed. One of the critical findings that led to the rejection of the event memory model and to this proposal concerning contextual conditioning was the failure to observe reinstatement of conditioned suppression to an extinguished CS when the reinstatement shock US presentations occurred in an irrelevant context (Bouton, 1984; Bouton \& Bolles, 1979; Bouton $\&$ King, 1983). In other words, reinstatement of conditioned suppression depended critically upon testing the extinguished CS in a dangerous context rather than upon the presentations of the shock per se.

However, this conclusion may be specific to the use of a conditioned suppression procedure. For instance, Schachtman, Brown, and Miller (1985) made rats sick after ingestion of a novel taste and then repeatedly presented this taste in the absence of illness. The induction and loss of the taste aversion took place in the home cages, in which high familiarity presumably minimized their associability with illness. These investigators then made some of the rats sick in a different context before testing them for intake of the extinguished taste in the home cages. The important outcome was a reinstatement of the taste aversion, indicating that this effect did not depend upon the extinguished CS being tested in a conditioned context or even upon the original taste-illness association having been formed against a background of contextual (home cage) conditioning. Moreover, there have been a number of reports in which rats have been subjected to fear conditioning of a context (e.g., the black compartment of a black-white shuttlebox) and then exposed to that context in the absence of the shock US. These rats have then been shocked in a different context before being tested for performance in the shuttlebox. There is considerable evidence that rats subjected to shock in the other context show a reinstatement of extinguished fear responding when tested in the shuttlebox: They take longer to enter the black compartment than rats for which fear of the black compartment was extinguished but that were not shocked in the other context, or rats not subjected to the original fear conditioning but that were shocked in the other context (e.g., Lashley, Richardson, \& Riccio, 1987; MacArdy \& Riccio, 1995). This evidence for reinstatement of fear to the black compartment of a shuttlebox (when rats were shocked elsewhere) or of a taste aversion in the home cages (when rats were made sick elsewhere) is consistent with the event memory model. This holds that extinction of conditioned performance is mediated, in part, by a depression of the US representation, and that reinstatement of this responding by US presentations is due to a restoration of that representation (Rescorla, 1979; but see Kasprow, Schachtman, Cacheiro, \& Miller, 1984).

In the present experiments, rats were shocked in the black but not the white compartment of a shuttlebox and then exposed to the black compartment in the absence of shock. Subsequently, shock was presented in a second context before the rats were tested for fear responding in the shuttlebox. We used a number of techniques to modify the levels of fear conditioned to the second context in order to determine the conditions that result in reinstatement of responding to an extinguished context. The prediction of Bouton's proposal concerning the role of contextual conditioning as a critical determinant of responding is that reinstatement of extinguished performance in the original context will vary with the level of fear conditioned to the second context as well as the stimulus generalization between the two contexts. In contrast, the event memory model predicts that reinstatement of extinguished performance in the original context may be dissociated from the level of fear conditioned to the second context. That is, from the perspective of the event memory model, reinstatement will occur if the US representation is restored, independent of any conditioning to the context that may occur.

\section{GENERAL METHOD}

\section{Subjects}

Experimentally naive, male, inbred Wistar rats were used. The rats weighed between 280 and $425 \mathrm{~g}$, and were obtained from the colony of Specific-Pathogen-Free rats maintained by the Combined University Laboratory Animal Services (Sydney, Australia). They were housed in groups of eight in plastic boxes $(65 \times 40 \times 22 \mathrm{~cm})$ with food and water continuously available. The boxes were kept in an air-conditioned colony room under natural lighting. All experimental procedures occurred between 11 a.m. and 5 p.m. All rats were handled 3-5 min each day across 5 days before initiation of any experiment. All experimental procedures followed the ethical guidelines established by the American Psychological Association, and were approved by the Animal Care and Ethics Committee at the University of New South Wales.

\section{Apparatus}

Three different chambers, located in three separate rooms, were used. Training, extinction, and passive avoidance testing took place in a black-white Perspex shuttlebox $(20 \times 40 \times 18 \mathrm{~cm}$, height $\times$ length $\times$ width). The floor of the shuttlebox consisted of stainless steel rods ( $2 \mathrm{~mm}$ in diameter spaced $10 \mathrm{~mm}$ apart, center to center). The shuttlebox was divided into two equal compartments by a partition with a guillotine door $(7 \times 6 \mathrm{~cm})$. One compartment was 
white with a clear Perspex hinged lid, and the other compartment was black with a black hinged lid. The shuttlebox was located in a dimly illuminated, noisy room; a $15-\mathrm{W}$ bulb suspended $30 \mathrm{~cm}$ above the center of the white compartment was the only illumination in the room and 70 to $75-\mathrm{dB}$ white noise (Bruel and Kjaer sound level meter Type 2235) was always present. Unscrambled (alternate grids connected), constant-current shock could be delivered through the floor in the black compartment via a Coulbourn shock generator (Model E13-01), and tap water was used to clean the shuttlebox after the removal of each rat.

The pretest shock (i.e., reinstatement cue) was administered in a smaller chamber $(20 \times 12 \times 12 \mathrm{~cm})$ than that used in training. The rear wall, ceiling, and door of this chamber were made of clear Perspex, and the two side walls were made of wire screen. The floor consisted of stainless steel rods $(2 \mathrm{~mm}$ in diameter spaced $12.5 \mathrm{~mm}$ apart, center to center). Unscrambled shock could be delivered to the floor of the chamber by a custom-built constant-current shock generator. This chamber was located in a wooden cabinet in a soundattenuating room. The room was illuminated by red fluorescent lighting located in the ceiling, while the chamber was illuminated by a $60-\mathrm{W}$ incandescent bulb mounted on the back wall of the wooden cabinet; there was no white noise present. A $1 \%$ almond essence solution was used to clean the chamber upon the removal of each rat.

Rats in the pseudotrained condition received their "trainingequivalent" shocks in a standard operant chamber $(20 \times 23 \times$ $21 \mathrm{~cm}$ ) in a room different from that used for training or the reinstatement shock. The front and rear walls of this chamber, as well as the hinged lid, were constructed of clear Perspex, and the end walls were made of stainless steel. The floor consisted of stainless steel rods ( $2 \mathrm{~mm}$ in diameter spaced $10 \mathrm{~mm}$ apart, center to center). Unscrambled shock from a custom-built constant-current generator could be delivered to the floor of the operant chamber. Acetic acid $(0.5 \%)$ was used to clean the chamber upon the removal of each rat. The room housing this chamber was illuminated by standard incandescent lights located in the ceiling, and there was no white noise present.

\section{Procedure}

All experiments consisted of three replications except Experiment 2, which consisted of two replications. All data were pooled across replications for analysis.

Training. On Day 1, a Pavlovian differential fear conditioning procedure was used. This consisted of placing each rat in the black side of the shuttlebox, with the door down, for $1 \mathrm{~min}$ and during that time administering three unsignaled shocks $(0.6 \mathrm{~mA}, 1-\mathrm{sec}$ duration in Experiment 1; $0.5 \mathrm{~mA}, 1$-sec duration in all other experiments). These shocks were administered after 10,30, and $40 \mathrm{sec}$. After this 1-min period, rats were placed on the white side of the shuttlebox with the door down, for 2 min, during which time no shock was presented. This sequence was then immediately repeated. Thus, training lasted $6 \mathrm{~min}$, and six shocks were administered during two 1-min sessions while the subject was confined to the black side of the apparatus.

A pseudotrained condition was included in the design of Experiments 1 and 3. In this condition, rats were exposed to the blackwhite shuttlebox using the same procedure as above, but no shocks were administered. At least $1 \mathrm{~h}$ after exposure to the black-white shuttlebox, these rats were placed in the operant chamber described above and given six inescapable shocks during a 2-min period. The shocks were of the same intensity and duration as those used in the black-white shuttlebox, and occurred after 10, 30, and $40 \mathrm{sec}$ of each 1-min period.

Extinction. On Day 2, rats in relevant conditions received a nonreinforced exposure to the black compartment of the shuttlebox (for $10 \mathrm{~min}$ in Experiment 1;8 min in all other experiments). No shocks were delivered during this time. Rats that did not receive this extinc- tion treatment were placed in an opaque white bucket $(34 \times 40 \mathrm{~cm}$; diameter $\times$ height), with paper pellet bedding spread across the floor and holes drilled in the lid, for an equivalent length of time.

Pretest reinstatement US. On Day 3, rats scheduled to receive the reinstatement shock US were placed in the smaller chamber described above and given a single shock (the same intensity as that used in training: $0.6 \mathrm{~mA}$ in Experiment $1,0.5 \mathrm{~mA}$ in all other experiments; 1 -sec duration in all cases). The length of exposure to the chamber before and after shock varied both within and between experiments (see the respective procedural tables). Rats were then removed and returned to their home cage. Rats not receiving the reinstatement US were placed in the same apparatus for an equivalent period of time, but were not shocked.

Passive avoidance testing. On Day 4, all rats were tested in the black-white shuttlebox. Each rat was placed in the white compartment facing away from the door. Ten seconds later, the door was raised and latency to cross into the black compartment (all four paws) was measured. Rats that did not cross within 10 min were removed from the apparatus and assigned a score of $600 \mathrm{sec}$. The total time spent in the white compartment of the shuttlebox (TTW) was also recorded. Since rats normally enter the black compartment relatively quickly, long latencies are taken as evidence of retention of the association between the black compartment and shock. Stopwatches were used to measure the latency to cross into the black compartment as well as the total time spent in the white compartment. Statistical analyses of the latency and TTW measures yielded the same results in all experiments; therefore, only the latency data are reported.

Reinstatement context testing. On Day 5, all rats were placed in the context where the pretest reinstatement US had been administered and their behavior was videotaped across $2 \mathrm{~min}$. The level of freezing displayed was later measured with a time-sampling procedure where the rat's behavior was scored as "freezing" or "not freezing" every $3 \mathrm{sec}$. Freezing was defined as the absence of all movement except that necessary for respiration (Fanselow, 1980). The percentage of all samples scored as freezing was determined for each subject. The videotape records of a random sample of $20 \%-25 \%$ of the subjects from each experiment were scored by a second observer who was blind to their treatment condition. The interrater reliability on the scores for these 47 rats was .97 .

Statistical analysis. In all cases, group differences were considered to be significant only if $p<.05$. Because some groups had a high proportion of ceiling scores on the passive avoidance test, nonparametric procedures were used to analyze these data. In each experiment, a Kruskall-Wallis analysis of variance (ANOVA) was performed to determine whether there were any group differences, and follow-up pairwise comparisons were made with the MannWhitney $U$ test. Because there were few ceiling (or floor) scores for the freezing measure, standard parametric ANOVAs were used to analyze these data. The overall error rate for the subsequent pairwise comparisons was maintained at $p<.05$ with the Bonferroni procedure.

\section{EXPERIMENT 1}

If, as proposed by Bouton (1994), postextinction reinstatement is due to the contextual conditioning produced by the reinstatement treatment US, then treatments designed to reduce this new learning should reduce the reinstatement effect. In contrast, if postextinction reinstatement is due to the restoration of the US representation, as assumed by Rescorla (1979), then these treatments should not affect the reinstatement effect provided that they do not also cause a further depression of the US rep- 
Table 1

Design Summary for Experiment 1

\begin{tabular}{|c|c|c|c|c|c|c|c|}
\hline Group & Training & Extinction & $\begin{array}{c}\text { Time } \\
\text { Before }^{a}\end{array}$ & $\begin{array}{c}\text { Reinstatement } \\
\text { US }\end{array}$ & $\begin{array}{l}\text { Time } \\
\text { After }^{\mathrm{b}}\end{array}$ & Test 1 & Test $2^{c}$ \\
\hline ImmUS & $\mathrm{B}+/ \mathrm{W}-$ & $B-$ & 0.0 & + & 0 & $\mathrm{~B} / \mathrm{W}$ & ReinCon \\
\hline DelUS & $\mathrm{B}+/ \mathrm{W}-$ & $\mathrm{B}-$ & 0.5 & + & 0 & $\mathrm{~B} / \mathrm{W}$ & ReinCon \\
\hline Train & $\mathrm{B}+/ \mathrm{W}-$ & buckets & $0.5^{f}$ & - & 0 & $\mathrm{~B} / \mathrm{W}$ & ReinCon \\
\hline TrainExt & $\mathrm{B}+/ \mathrm{W}-$ & B- & $0.5^{f}$ & - & 0 & $\mathrm{~B} / \mathrm{W}$ & ReinCon \\
\hline Pseudo & $B-/ W-d$ & $\mathrm{~B}-$ & 0.5 & + & 0 & $\mathrm{~B} / \mathrm{W}$ & ReinCon \\
\hline Naive & handle & handle & 0.5 & + & 0 & $\mathrm{~B} / \mathrm{W}$ & ReinCon \\
\hline
\end{tabular}

Note-Training, extinction, and Test 1 occurred in the black (B) and white (W) shuttlebox. Reinstatement treatment and Test 2 occurred in a different context (ReinCon). a Time (minutes) spent in the reinstatement context prior to delivery of the US $(+)$. ${ }^{b}$ Time (minutes) spent in the reinstatement context after delivery of the US $(+)$. c Test for freezing to the context in which the reinstatement US was given. d Rats in Group Pseudo were given a nonreinforced exposure to the black-white shuttlebox followed by reinforced exposure to an alternate third context. $\quad{ }^{e}$ Rats in Group Naive were run after all other groups. ${ }^{\mathrm{f}}$ Time (minutes) spent in the reinstatement context; no US was delivered.

resentation. To examine this issue, the present experiment took advantage of a phenomenon referred to as the immediate shock freezing deficit. There are several demonstrations that rats shocked immediately after being placed in a novel context do not freeze when reexposed to that context, whereas rats shocked after a delay exhibit substantial levels of freezing (e.g., Blanchard, Fukanaga, \& Blanchard, 1976; Fanselow, 1980; Kiernan, Westbrook, \& Cranney, 1995; but see Bevins, McPhee, Rauhut, \& Ayres, 1997). The freezing deficit in the immediate-shock condition has been interpreted as being due to an encoding failure; rats in this condition do not form an association between the context and the shock (Fanselow, 1986, 1990; Kiernan \& Westbrook, 1993; but see Bevins et al., 1997, for an alternate explanation). Therefore, if new learning is the critical determinant of whether postextinction reinstatement occurs, then rats in the immediate shock condition should not exhibit the effect. In contrast, if postextinction reinstatement is due to restoration of the US representation, then rats in both the immediate and the delayed shock conditions should exhibit the effect.

There were five groups in this experiment (Table 1). Two groups were trained, extinguished, and given the reinstatement US. One of these two groups received the US immediately upon being placed in the context (Group ImmUS) and the other received the shock after a 30-sec delay (Group DelUS). Previous research (e.g., Kiernan \& Westbrook, 1993) suggests that these two groups should subsequently exhibit markedly different levels of freezing to that context. There were three control groups. Rats in one of these were simply trained and tested in the black-white shuttlebox (Group Train). Performance of this group would indicate whether with these training procedures rats acquire fear of (i.e., avoid) the black compartment. The rats in a second control group were trained and tested in the black-white shuttlebox, but these rats also received the extinction treatment (Group TrainExt). Performance of this group would show that (1) the extinction treatment was effective in reducing avoidance of the black compartment, and (2) any postextinction reinstatement effect observed in the groups given the reinstatement US was not simply due to spontaneous recovery. Rats in the final control condition received pseudotraining, extinction, and the reinstatement US prior to test (Group Pseudo). The reinstatement US was given after a 30 -sec delay in this condition. Performance of this group would show whether any observed increase in passive avoidance performance in Groups ImmUS and DelUS was due to simple generalization or was dependent upon prior fear conditioning to the black compartment. All groups consisted of 10 rats except for the pseudotrained group, which had 8.

\section{Results and Discussion}

Passive avoidance test. The results of the passive avoidance test are shown in the top panel of Figure 1. An overall analysis indicated that there were significant group differences in the latencies to cross into the black compartment $(H=31.86)$. Subsequent pairwise comparisons revealed that the Train group differed from the TrainExt group $(U=1)$, showing that the extinction treatment was effective in reducing the fear of the black compartment. Further, Group DelUS was different from the TrainExt group $(U=13)$, but not different from the Train group $(U=28.5)$, showing that the delayed shock was effective in reinstating the avoidance of the black compartment. In marked contrast, rats given the immediate reinstatement US failed to show the reinstatement effect. That is, there were no significant differences between the ImmUS group and the TrainExt group $(U=30.5)$, but there were significant differences between the ImmUS group and the Train group $(U=2)$. In addition, the difference between Group DelUS and Group ImmUS was significant $(U=$ 21.5). Finally, rats in Group Pseudo had shorter latencies than the rats in the DelUS group $(U=0)$, showing that the enhanced performance caused by the delayed reinstatement US was restricted to rats previously trained to fear the black compartment. 


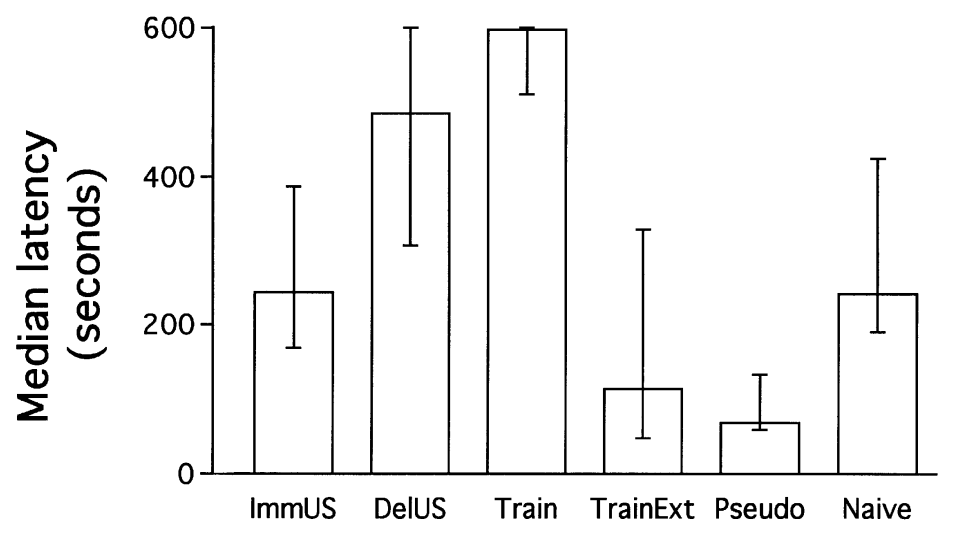

Condition

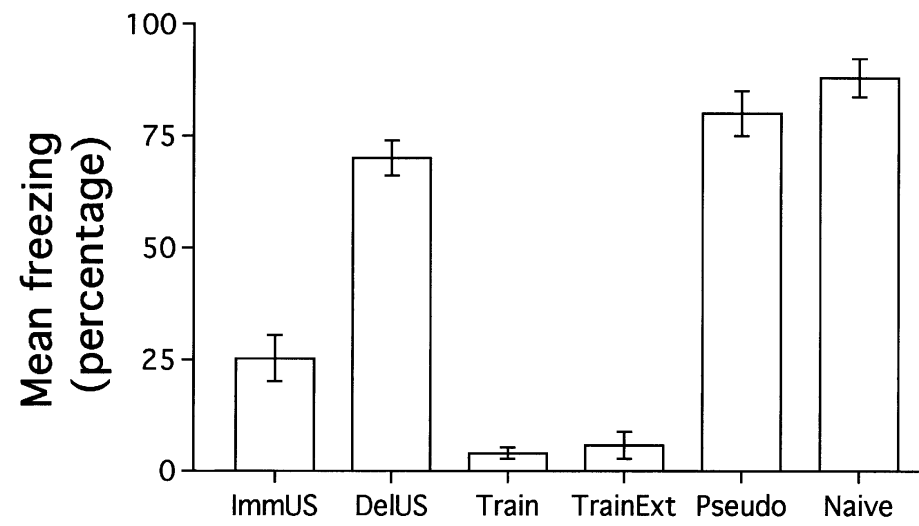

\section{Condition}

Figure 1. Median (+ interquartile range) latency to cross into the black compartment of a black-white shuttlebox (top panel) and mean ( $\pm S E M$ ) percent time freezing in the reinstatement chamber (bottom panel) for rats in each of the groups in Experiment 1. All groups, except Groups Pseudo and Naive, were initially trained to fear the black compartment. This fear was subsequently extinguished in Groups ImmUS, DelUS, and TrainExt. Prior to test, Groups DelUS and Pseudo were placed in the reinstatement chamber and given a single shock after a 30-sec delay; Group ImmUS received the same shock immediately after being placed in the reinstatement context. Rats in Group Naive were run after all other groups.

The last comparison mentioned (i.e., Group Pseudo vs. Group DelUS) was taken as evidence that the reinstatement US affected passive avoidance performance only in rats trained to fear the black compartment. However, it must be noted that rats in Group Pseudo received preexposure to the black-white shuttlebox without being shocked there. This experience may have altered the effects of the reinstatement US. We therefore tested an additional group of rats $(n=8)$ that received the reinstatement shock, but that had not been preexposed to the black-white shuttlebox (Group Naive). We then compared the passive avoidance performance of this group with that shown by the two groups given the delayed reinstatement US (i.e., Groups DelUS and Pseudo). The ANOVA indicated that there were significant group differences $(H=17.55)$, and subsequent pairwise comparisons showed that Group DelUS exhibited significantly longer latencies than both of the other groups (largest $U=17$ ) and that Group Naive showed significantly longer latencies than Group Pseudo $(U=1.5)$.

Reinstatement context test. Freezing in the context in which the reinstatement US had been administered was measured $24 \mathrm{~h}$ after the passive avoidance test. The mean percentage of samples scored as freezing during the 
Table 2

Design Summary for Experiment 2

\begin{tabular}{llcccccc}
\hline \multicolumn{1}{c}{ Group } & Training & Extinction & $\begin{array}{c}\text { Time } \\
\text { Before }^{\mathrm{a}}\end{array}$ & $\begin{array}{c}\text { Reinstatement } \\
\text { US }\end{array}$ & $\begin{array}{c}\text { Time } \\
\text { After }^{\mathrm{b}}\end{array}$ & Test 1 & Test 2 $^{\mathrm{c}}$ \\
\hline Rein0.5-0 & B+/W- & B- & 0.5 & + & 0 & B/W & ReinCon \\
Rein0.5-2 & B+/W- & B - & 0.5 & + & 2 & B/W & ReinCon \\
Rein0.5-5 & B+/W- & B - & 0.5 & + & 5 & B/W & ReinCon \\
Rein0.5-20 & B+/W- & B- & 0.5 & + & 20 & B/W & ReinCon \\
NoRein & B+/W- & B - & $0.5^{\mathrm{d}}$ & - & 0 & B/W & ReinCon \\
\hline
\end{tabular}

Note-Training, extinction, and Test 1 occurred in the black (B) and white (W) shuttlebox. Reinstatement treatment and Test 2 occurred in a different context (ReinCon). a Time (minutes) spent in the reinstatement context prior to delivery of the US $(+)$. b Time (minutes) spent in the reinstatement context after delivery of the US $(+)$. ${ }^{c}$ Test for freezing to the context in which the reinstatement US was given. $\quad{ }^{\mathrm{d}}$ Time (minutes) spent in the reinstatement context; no US was delivered.

2-min exposure to this context is shown in the bottom panel of Figure 1. Both groups given the delayed shock (Groups DelUS and Pseudo) froze for $70 \%-80 \%$ of the session. In contrast, the group given the immediate shock (Group ImmUS) froze substantially less of the time, while the rats not given a reinstatement US (Groups Train and TrainExt) displayed essentially no freezing. Statistical analysis of these data confirmed that rats given a delayed shock showed more freezing than those given an immediate shock $[F(1,43)=111.5]$. This replicates the immediateshock freezing deficit reported by Fanselow and others (e.g., Fanselow, 1986; Kiernan \& Westbrook, 1993). However, the immediate shock condition did result in some freezing; that is, rats not receiving a reinstatement US froze less during this test than did rats receiving either the delayed or the immediate shock $[F(1,43)=325.79$ and 19.48, respectively]. The latter result supports the recent findings of Bevins et al. (1997) that under some circumstances rats in the immediate-shock condition can acquire some association between the context and the shock. Clearly, however, the level of contextual conditioning was much less in the immediate-shock condition than in the delayed-shock condition. Finally, rats receiving a delayed reinstatement US (Groups DelUS, Pseudo, and Naive) all exhibited substantial and similar levels of context freezing (means of $67 \%, 80 \%$, and $87.9 \%$, respectively). Nevertheless, these groups differed significantly in terms of their performance on the passive avoidance test.

The results of Experiment 1 provide support for the hypothesis that postextinction reinstatement is mediated by new learning occasioned by the reinstatement US, and fail to support the US restoration view. Rats placed into a context and given an immediate shock displayed little fear of that context and also failed to show the reinstatement effect on the passive avoidance test. In contrast, rats placed into a context and given the reinstatement US after a 30-sec delay displayed substantial fear of that context and also a substantial reinstatement effect. These observations were also supported by a Pearson product moment correlation $(r=.564, p<.01)$ between the data from the passive avoidance and freezing tests for animals in the ImmUS and DelUS groups (data were collapsed across groups). Note that the effects of the delayed reinstate- ment US depended on the rat's previous experience with the black-white shuttlebox. Specifically, rats with no previous experience with the shuttlebox (Group Naive) exhibited longer latencies to enter the black compartment than those shown by rats previously exposed to the shuttlebox in the absence of shock (Group Pseudo) but shorter latencies than those displayed by rats shocked and then extinguished in the black compartment (Group DelUS). Taken together, these results show that the reinstatement effect is not a consequence of simple generalization of fear from the reinstatement context to the test context.

\section{EXPERIMENT 2}

If the reinstatement effect is due to contextual conditioning resulting from the reinstatement US, then extinction of that learning prior to assessment of reinstatement should attenuate the magnitude of the effect. MacArdy and Riccio (1995) reported data consistent with this expectation (see also Bouton \& Bolles, 1979). Specifically, they found that rats given a 5-min extinction session in the reinstatement context immediately after being shocked there exhibited shorter latencies on the passive avoidance test than did rats that received the reinstatement shock but not the extinction session. However, MacArdy and Riccio did not measure fear responding in the reinstatement context in order to confirm that extinction of fear actually occurred. In addition to providing independent evidence that the extinction session did reduce fear of the reinstatement context, Experiment 2 was designed to provide a parametric examination of the relation between the duration of the extinction session and the reinstatement effect.

There were five groups in this experiment (Table 2). Rats in all groups were trained to fear the black compartment of the black-white shuttlebox, and then had this fear extinguished (see the General Method section for details). On the day after the extinction session, rats in four groups were shocked $30 \mathrm{sec}$ after being placed in the reinstatement context. These four groups differed only in the amount of time in the context after the reinstatement; that is, rats remained in the reinstatement context for $0,2,5$, or 20 min after the shock. Rats in a fifth group did not receive the reinstatement shock and were included 


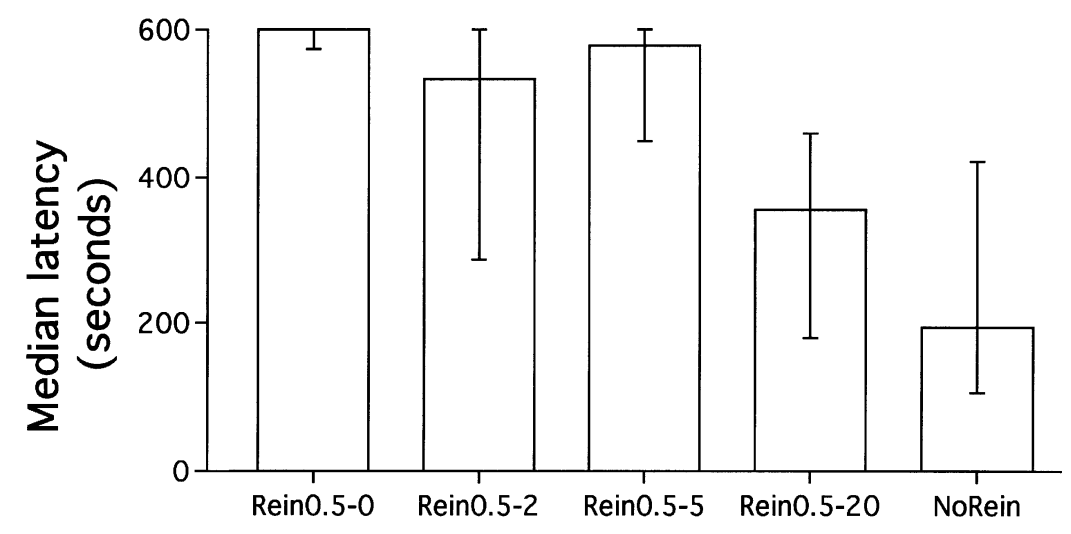

\section{Condition}

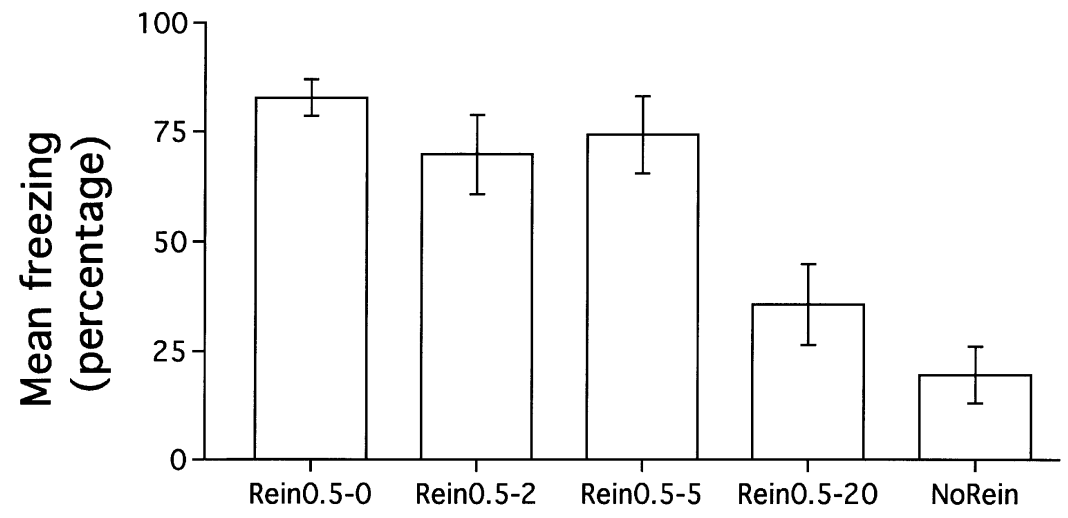

\section{Condition}

Figure 2. Median (+ interquartile range) latency to cross into the black compartment of a black-white shuttlebox (top panel) and mean $( \pm S E M)$ percent time freezing in the reinstatement chamber (bottom panel) for rats in Experiment 2. All rats were initially trained to fear the black compartment, and this fear was subsequently extinguished in all groups. Prior to test, all groups, except for Group NoRein, were placed in the reinstatement chamber and given a single shock after a 30-sec delay. Rats in different groups remained in the reinstatement chamber for $0,2,5$, or 20 min following this shock.

to ensure that any observed reinstatement effect was not simply due to spontaneous recovery. All groups consisted of 10 rats except for the group that remained in the reinstatement context for $20 \mathrm{~min}$, which had 8 rats.

\section{Results and Discussion}

Passive avoidance test. The results of the passive avoidance test are shown in the top panel of Figure 2. An overall analysis indicated that there were significant group differences on this test $(H=18.55)$. Subsequent pairwise comparisons showed that the group that was removed from the reinstatement context immediately after the shock did not differ from the groups removed either 2 or $5 \mathrm{~min}$ after the shock (smallest $U=24$ ). However, the group that remained in the reinstatement context for $20 \mathrm{~min}$ and the group that did not receive the reinstatement shock both showed shorter latencies than the group that was removed from the reinstatement context immediately after the shock (Rein0.5-0, largest $U=8$ ). The difference in latencies between the Rein0.5-0 group and the NoRein group demonstrates that the reinstatement was effective in reinstating extinguished performance, confirming the results obtained in the previous experiment. The difference between the group that was removed from the reinstatement context immediately after the shock (Group Rein0.50 ) and the group that remained in the reinstatement context for 20 min after the shock (Group Rein0.5-20) demonstrates that this period of context extinction was effective in attenuating the reinstatement effect. In fact, the difference between the group that remained in the reinstate- 
Table 3

Design Summary for Experiment 3

\begin{tabular}{llcccccr}
\hline Group & Training & Extinction & $\begin{array}{c}\text { Time } \\
\text { Before }^{\mathrm{a}}\end{array}$ & $\begin{array}{c}\text { Reinstatement } \\
\text { US }\end{array}$ & $\begin{array}{c}\text { Time } \\
\text { After }^{\mathrm{b}}\end{array}$ & Test 1 & Test 2 $^{\mathrm{c}}$ \\
\hline Rein0.5-0 & B+/W- & B- & 0.5 & + & 0 & B/W & ReinCon \\
Rein20-0 & B+/W- & B- & 20.0 & + & 0 & B/W & ReinCon \\
Train & B+/W- & buckets & $0.5^{\mathrm{e}}$ & - & 0 & B/W & ReinCon \\
TrainExt & B+/W - & B - & $0.5^{\mathrm{e}}$ & - & 0 & B/W & ReinCon \\
Pseudo & B-/W-d & B- & 0.5 & + & 0 & B/W & ReinCon \\
\hline
\end{tabular}

Note-Training, extinction, and Test 1 occurred in the black (B) and white (W) shuttlebox. Reinstatement treatment and Test 2 occurred in a different context (ReinCon). ${ }^{a}$ Time (minutes) spent in the reinstatement context prior to delivery of the reinstatement US $(+)$. b Time (minutes) spent in the reinstatement context after delivery of the reinstatement US $(+)$. ${ }^{\mathrm{c}}$ Test for freezing to the context in which the reinstatement US was given. ${ }^{\mathrm{d}}$ Rats in Group Pseudo were given a nonreinforced exposure to the black-white shuttlebox followed by reinforced exposure to an alternate third context. eTime (minutes) spent in the reinstatement context; no US was delivered.

ment context for $20 \mathrm{~min}$ and the group that did not receive a reinstatement shock was not significant $(U=27)$.

Reinstatement context test. The mean percentage of samples scored as freezing is shown in the bottom panel of Figure 2. Rats that remained in the reinstatement context for 20 min after the shock displayed less freezing than did rats in the other three reinstatement groups $[F(1,43)=$ 17.65], but did not differ from the rats not given the reinstatement shock $[F(1,43)=2.02]$, demonstrating that the 20-min extinction session was effective in reducing the level of fear of that context.

The results of this experiment confirm that extinction of fear of the reinstatement context attenuates the reinstatement effect (Bouton \& Bolles, 1979; MacArdy \& Riccio, 1995). In the present experiment, the rats that failed to display fear of the reinstatement context because of a 20-min extinction exposure also failed to show the reinstatement effect. Further evidence for this claim is provided by the Pearson product moment correlation $(r=.72$, $p<.01$ ) between the data from the passive avoidance and freezing tests. This finding is consistent with the hypothesis that new learning mediates reinstatement of extinguished fear conditioning, but it could also be explained by the independent supposition that extinction of the reinstatement context provoked a further depression of the US representation.

\section{EXPERIMENT 3}

The results of the previous two experiments show that manipulations that reduce fear of the reinstatement context also reduce the reinstatement of the extinguished avoidance response. This relation was further explored in the present experiment, which manipulated the level of fear of the reinstatement context by exposing some subjects to that context prior to administering the reinstatement US. It was predicted that rats given a long exposure to the reinstatement context prior to administration of the shock would exhibit less fear of that context, and, therefore, less reinstatement of the extinguished fear of the black compartment of the shuttlebox.

There were five groups in this experiment (Table 3 ). One group received the standard shuttlebox training, extinction, and reinstatement US (Group Rein0.5-0). A second group was also trained, extinguished, and given the reinstatement treatment. However, instead of receiving the reinstatement shock $30 \mathrm{sec}$ after being placed in the reinstatement context, as was the case in Group Rein0.5-0, rats in Group Rein20-0 were given the shock after a 20min delay. Rats in Group Rein20-0 were expected to exhibit less freezing when returned to the reinstatement context than rats in Group Rein0.5-0 (Westbrook, Good, \& Kiernan, 1994), and, on the basis of the results of Experiments 1 and 2, to exhibit less reinstatement when tested on the passive avoidance task. The remaining three groups were the same control groups as those used in Experiment 1: Groups Train, TrainExt, and Pseudo. All groups consisted of 10 rats except for the Pseudo and Train groups, which had 8 subjects each.

\section{Results and Discussion}

Passive avoidance test. The results of the passive avoidance test are shown in the top panel of Figure 3. Both the Rein0.5-0 and Train groups displayed long latencies to cross into the black compartment compared with the TrainExt and Pseudo groups, which exhibited relatively short latencies. The group of primary interest, Group Rein 20-0, had long latencies. That is, these subjects exhibited reinstatement. Statistical analysis of these data revealed group differences $(H=17.43)$. Pairwise comparisons showed that Group Rein0.5-0 was different from the TrainExt group $(U=0)$, once again indicating that the reinstatement shock was effective in reinstating the fear of the black compartment. In addition, Group Rein20-0 was different from the TrainExt group $(U=19)$, but not from Group Rein0.5-0 (U=42), showing that the 20-min 


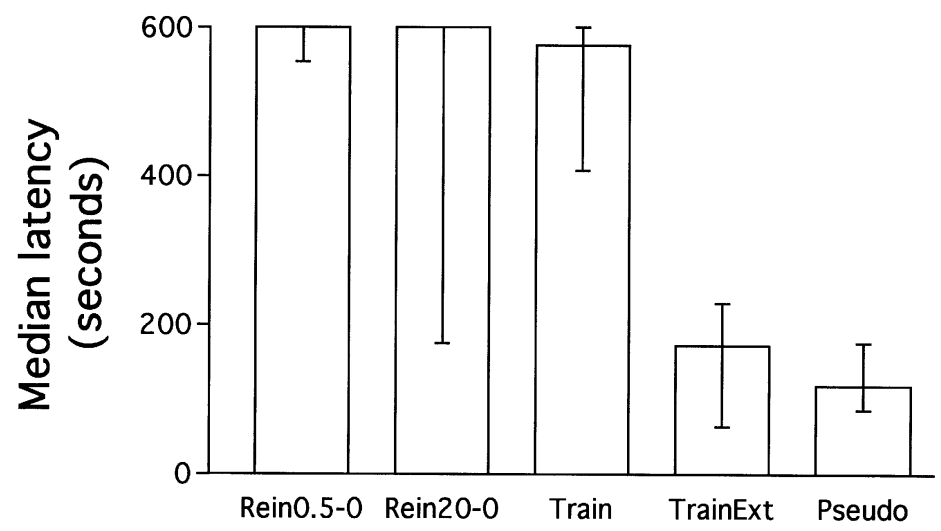

Condition

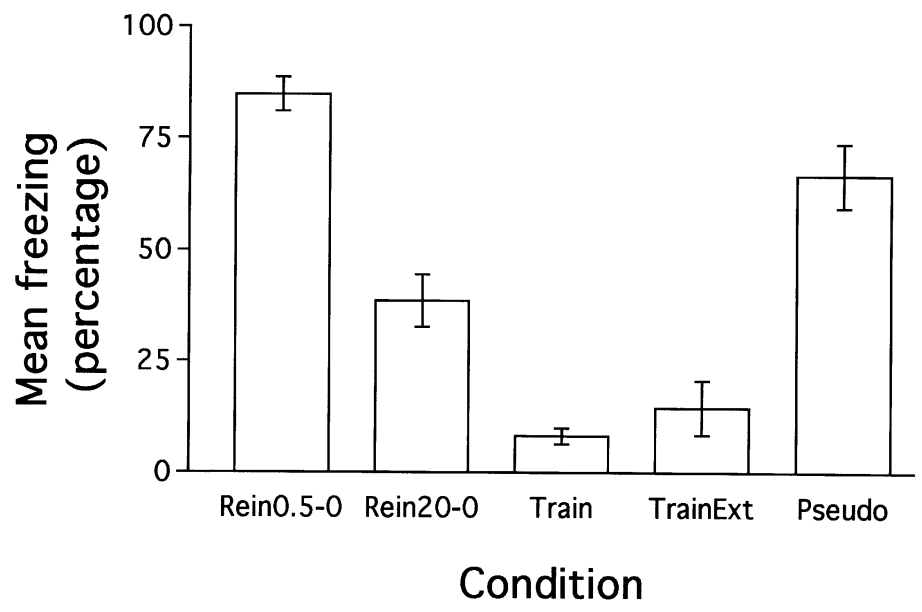

\begin{abstract}
Figure 3. Median (+ interquartile range) latency to cross into the black compartment of a black-white shuttlebox (top panel) and mean $( \pm S E M)$ percent time freezing in the reinstatement chamber (bottom panel) for rats in Experiment 3. All groups, except Group Pseudo, were initially trained to fear the black compartment. This fear was subsequently extinguished in Groups Rein0.5-0, Rein20-0, and TrainExt. Prior to test, Groups Rein0.5-0 and Pseudo were placed in the reinstatement chamber and given a single shock after a 30-sec delay; Group Rein20-0 received the same shock after a 20-min delay.
\end{abstract}

context preexposure did not significantly attenuate the effectiveness of the reinstatement shock in reinstating fear of the black compartment.

Reinstatement context test. The mean percentage of samples scored as freezing is shown in the bottom panel of Figure 3. As can be seen, rats given a 20 -min preexposure to the reinstatement context displayed much less freezing than rats shocked after a 30 -sec delay $[F(1,41)=$ 33.96]. However, this attenuation of fear conditioning to the reinstatement context was not complete in that the 20-min preexposed rats froze more than rats not given a shock $[F(1,41)=18.35]$.

The results of this experiment were not entirely as predicted. Rats given the reinstatement shock after a 20-min delay exhibited less freezing to the reinstatement context than did rats given the shock after a 30-sec delay. However, and of more central importance to the present experiments, the rats given the reinstatement shock after a 20-min delay still exhibited the reinstatement effect when tested on the passive avoidance task. In other words, the correspondence between reinstatement of the extinguished avoidance response and fear of the reinstatement context found in Experiments 1 and 2 was not observed in this experiment.

One possible explanation for this discrepancy would be to appeal to a threshold notion. That is, subjects exhibiting a level of fear of the reinstatement context over some threshold will display the reinstatement effect whereas those below that threshold will not. However, this hy- 
Table 4

Design Summary for Experiment 4

\begin{tabular}{llcccccr}
\hline Group & Training & Extinction & $\begin{array}{c}\text { Time } \\
\text { Before }^{\mathrm{a}}\end{array}$ & $\begin{array}{c}\text { Reinstatement } \\
\text { US }\end{array}$ & $\begin{array}{c}\text { Time } \\
\text { After }^{\mathrm{b}}\end{array}$ & Test 1 & Test 2c $^{\mathrm{c}}$ \\
\hline Rein0.5-0 & B+/W - & B - & 0.5 & + & 0 & B/W & ReinCon \\
Rein20-0 & B+/W - & B - & 20.0 & + & 0 & B/W & ReinCon \\
Rein20-20 & B+/W - & B - & 20.0 & + & 20 & B/W & ReinCon \\
\hline
\end{tabular}

Note-Training, extinction, and Test 1 occurred in the black (B) and white (W) shuttlebox. Reinstatement treatment and Test 2 occurred in a different context (ReinCon). a Time (minutes) spent in the reinstatement context prior to delivery of the reinstatement US $(+)$. b Time (minutes) spent in the reinstatement context after delivery of the reinstatement US $(+) . \quad{ }^{c}$ Test for freezing to the context in which the reinstatement US was given.

pothesis is not supported by the data. Specifically, rats in the 20-min preexposure condition in this experiment exhibited levels of freezing in the reinstatement context comparable to those of rats in Experiment 2 that were given a 20 -min extinction session (both froze about $40 \%$ of the time). Yet these two groups exhibited markedly different responses on the passive avoidance test; the preexposed rats failed to cross into the black compartment, whereas the extinguished rats crossed into that compartment with relatively short latencies.

Another possible explanation for the discrepancy between freezing and passive avoidance performance in Group Rein20-0 involves the mechanism responsible for latent inhibition. Traditional accounts of latent inhibition posit that this effect is due to an encoding failure (e.g., Mackintosh, 1975; Pearce \& Hall, 1980). Recent research, however, has provided evidence for the view that latent inhibition does not involve a failure to acquire an association between the CS and US. For example, Kraemer and Roberts (1984) used a conditioned taste aversion procedure to examine latent inhibition in rats. These investigators reported that taste preexposure reduced the conditioned aversion (i.e., produced latent inhibition) if the rats were tested 1 day after conditioning but not if they were tested 21 days after conditioning. This loss of the latent inhibition effect with the delayed test shows that the preexposed rats did initially acquire the association between the taste and illness even though it was not expressed at the 1-day retention interval.

It is suggested that in the present study the preexposed rats acquired two memories of the reinstatement context: (1) that it is a relatively safe place-because of the 20min preexposure, and (2) that it is a relatively dangerous place-because of the shock delivered after the 20-min preexposure. The association between the reinstatement context and the shock is behaviorally silent, at least after a short retention interval, when rats are returned to that context. However, when animals are tested in a different context - the black-white shuttlebox for example - then this association is expressed, causing reinstatement of the fear memory of the black compartment. The difficulty with this approach, however, is in specifying the exact conditions in which "behaviorally silent" associations are capable of signaling retrieval of a particular CS-US as- sociation. For example, extended exposure to the reinstatement context after the shock makes the contextshock association behaviorally silent, but this also attenuates the reinstatement effect (e.g., Experiment 2). Clearly, what is required is some formal specification of the conditions governing when behaviorally silent associations are capable of signaling retrieval and when they are not.

\section{EXPERIMENT 4}

This experiment had two aims. The first was to replicate the unexpected finding in the previous experiment that preexposure to the reinstatement context reduced freezing to that context but did not reduce the reinstatement of the extinguished avoidance response. The second aim was to examine whether the reinstatement effect in preexposed subjects was due to a behaviorally silent context-shock association. Specifically, if subjects given an extended preexposure to the reinstatement context nevertheless acquire a context-shock association (an association that is not expressed in the context freezing test, but that generalizes to the passive avoidance test), then giving these subjects an exposure to the reinstatement context after the shock (i.e., extinguishing fear of the context) should attenuate the reinstatement effect (see Experiment 2).

There were three groups in this experiment (Table 4). All rats were given training and extinction sessions in the shuttlebox, as well as a reinstatement shock. One group received the shock $30 \mathrm{sec}$ after being placed in the reinstatement context (Group Rein0.5-0), and the other two groups received the shock 20 -min after being placed in the context. One of the latter two groups remained in the reinstatement context for an additional $20 \mathrm{~min}$ after the reinstatement shock (Group Rein20-20), whereas the other group was removed immediately after the shock (Group Rein20-0). All groups consisted of 12 rats.

\section{Results and Discussion}

Passive avoidance test. The results of the passive avoidance test are shown in the top panel of Figure 4. Rats given the reinstatement shock after a 30-sec delay showed a complete reinstatement effect, as did rats given the shock after a 20-min delay and removed from the re- 


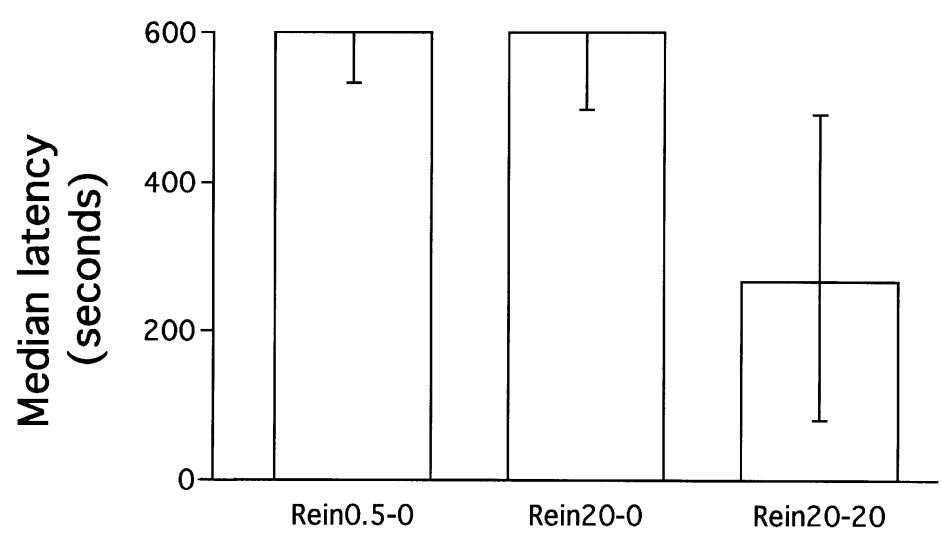

Condition

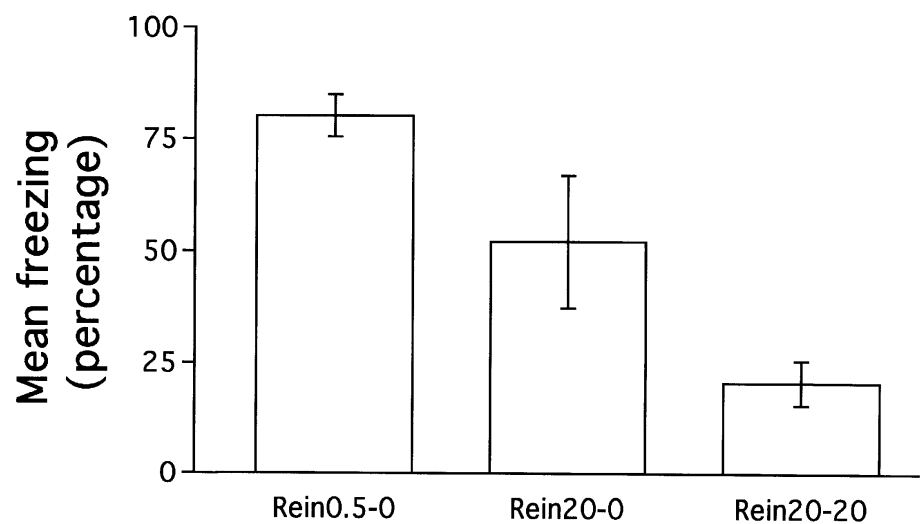

Condition

Figure 4. Median (+ interquartile range) latency to cross into the black compartment of a black-white shuttlebox (top panel) and mean $( \pm S E M)$ percent time freezing in the reinstatement chamber (bottom panel) for rats in Experiment 4. All groups were initially trained to fear the black compartment, and this fear was subsequently extinguished in all groups. Prior to test, rats in Group Rein0.5-0 were placed in the reinstatement chamber and given a single shock after a 30-sec delay. Rats in Groups Rein20-0 and Rein20-20 received the same shock after a 20-min delay. Rats in Group Rein20-20 remained in the reinstatement chamber for 20 min after the shock, whereas rats in the other groups were removed immediately after the shock.

instatement context immediately after the shock. The latter result replicates the finding of Experiment 3. Of particular interest, however, is the finding that rats given a 20-min extinction exposure to the reinstatement context after the shock crossed into the black compartment with relatively short latencies, indicating that reinstatement had been attenuated.

Statistical analysis confirmed that there were significant group differences $(H=14.6)$. Pairwise comparisons revealed that there were no significant differences between Groups Rein0.5-0 and Rein20-0 $(U=68.5)$, showing, as in Experiment 3, that the lengthy preexposure to the reinstatement context did not diminish the reinstatement effect. The Rein 20-0 group was different from the Rein20-20 group, however $(U=23.5)$, showing that the 20-min extinction exposure to the preexposed reinstatement context was successful in attenuating the reinstatement of the extinguished avoidance response.

Reinstatement context test. The median percentage of samples in the reinstatement context scored as freezing is shown in the bottom panel of Figure 4. As in the previous experiment, rats shocked after $30 \mathrm{sec}$ exhibited more freezing than rats shocked after $20 \min [F(1,33)=$ 22.26]. Further, those rats given the 20 -min extinction 
Table 5

Design Summary for Experiment 5

\begin{tabular}{|c|c|c|c|c|c|c|c|}
\hline Group & Training & Extinction & $\begin{array}{c}\text { Time } \\
\text { Before }^{\mathrm{a}}\end{array}$ & $\begin{array}{c}\text { Reinstatement } \\
\text { US }\end{array}$ & $\begin{array}{l}\text { Time } \\
\text { After }{ }^{\mathrm{b}}\end{array}$ & Test 1 & Test $2^{c}$ \\
\hline ToneRein $0.5-20$ & $\mathrm{~B}+/ \mathrm{W}-$ & $B-$ & 0.5 & Tone + & 20 & $\mathrm{~B} / \mathrm{W}$ & ReinCon \\
\hline ToneRein $0.5-0$ & $\mathrm{~B}+/ \mathrm{W}-$ & $\mathrm{B}-$ & 0.5 & Tone + & 0 & $\mathrm{~B} / \mathrm{W}$ & ReinCon \\
\hline TrainExt & $\mathrm{B}+/ \mathrm{W}-$ & $\mathrm{B}-$ & $0.5^{\mathrm{d}}$ & - & 0 & $\mathrm{~B} / \mathrm{W}$ & ReinCon \\
\hline
\end{tabular}

Note-Training, extinction, and Test 1 occurred in the black (B) and white (W) shuttlebox. Reinstatement treatment and Test 2 occurred in a different context (ReinCon). a Time (minutes) spent in the reinstatement context prior to delivery of the reinstatement US $(+)$. b Time (minutes) spent in the reinstatement context after delivery of the reinstatement US $(+) .{ }^{c}$ Test for freezing to the context in which the reinstatement US was given. ${ }^{\mathrm{d}}$ Time (minutes) spent in the reinstatement context; no US was delivered.

exposure to the reinstatement context exhibited even less freezing than rats given only the 20 -min preexposure session $[F(1,33)=11.01]$.

The results of this experiment replicated (1) the finding from Experiment 3 that extended exposure to the reinstatement context in advance of the shock did not attenuate the reinstatement effect, and (2) the finding from Experiment 2 that a 20-min nonreinforced exposure to the reinstatement context after the shock was effective in attenuating the reinstatement effect. The latter result supports the hypothesis that the preexposed rats do acquire an association between the context and shock even though that learning is not strongly expressed in the context freezing test. Many of the other demonstrations that support the claim that latently inhibited rats may acquire an association have involved delaying testing; subjects tested after a short retention interval exhibit latent inhibition, whereas subjects tested after a long interval do not (e.g., Ackil, Carman, Bakner, \& Riccio, 1992; Killcross, Kiernan, Dwyer, \& Westbrook, 1998; Kraemer \& Roberts, 1984). In the present experiment, however, evidence that latent inhibition does not result from an associative failure is provided by the finding that subjects preexposed to the reinstatement context still exhibited reinstatement when tested on the passive avoidance task.

\section{EXPERIMENT 5}

The results of the previous experiments suggest that rats that exhibit fear responses in the reinstatement context will show a reinstatement of fear to the extinguished black compartment of the shuttlebox. Further, rats for which fear of the reinstatement context has been extinguished will fail to show reinstatement. Does reinstatement depend upon rats being tested while currently afraid of something or upon them being afraid of another context? The present experiment used three groups to study this question (Table 5). All groups were given the standard fear conditioning and extinction sessions in the shuttlebox. Two groups received a reinstatement US while one did not (Group TrainExt). The reinstatement treatment in this experiment was comparable to the standard reinstatement treatment in the previous experiments (i.e., a single shock after a 30-sec delay), but in this experiment the shock was signaled. That is, a tone $(1500 \mathrm{~Hz}, 75 \mathrm{~dB}$; Scale A) was presented for the 10 -sec period preceding shock. Rats in both reinstatement groups were immediately removed from the reinstatement context following the shock. Rats in one of these groups were then returned to the reinstatement context for a 20-min context extinction session (Group ToneRein0.5-20), while the subjects in the other group were returned to their home cages (Group ToneRein0.5-0). The outcome of this treatment should be that rats in the first reinstatement group will be fearful of the tone but not the context, while rats in the second reinstatement group will be fearful of both the tone and the reinstatement context (unless the tone overshadowed the context). Therefore, if it is necessary for subjects to be afraid of the reinstatement context in order to reinstate the extinguished avoidance response, then only the rats in the second reinstatement group should exhibit the effect. Each group consisted of 10 subjects.

A novel context was used to assess fear of the auditory CS. This context was a clear Perspex box $(39 \times 30 \times$ $30 \mathrm{~cm}$ ) with a hinged front door and a stainless steel floor. This box was housed in a sound-attenuating wood chamber, painted white, that was open at the front. The room housing this novel context was illuminated with fluorescent ceiling lights, and an exhaust fan in the wood chamber provided low-level background noise. The CS test occurred shortly after the reinstatement context test on Day 5. During the CS test, the tone was presented for the last 2 min of a 4-min test period.

\section{Results and Discussion}

Passive avoidance test. The results of the passive avoidance test are shown in the top panel of Figure 5. A group difference was found $(H=7.45)$. Subsequent pairwise comparisons revealed that Group TrainExt was different from Group ToneRein0.5-0 ( $U=15.0)$, showing that the reinstatement shock was effective in reinstating passive avoidance. In addition, and of more interest, a difference was also found between Groups ToneRein0.50 and ToneRein0.5-20 $(U=21.5)$, showing that the extinction session in the reinstatement chamber was effective in attenuating the reinstatement effect. Finally, 


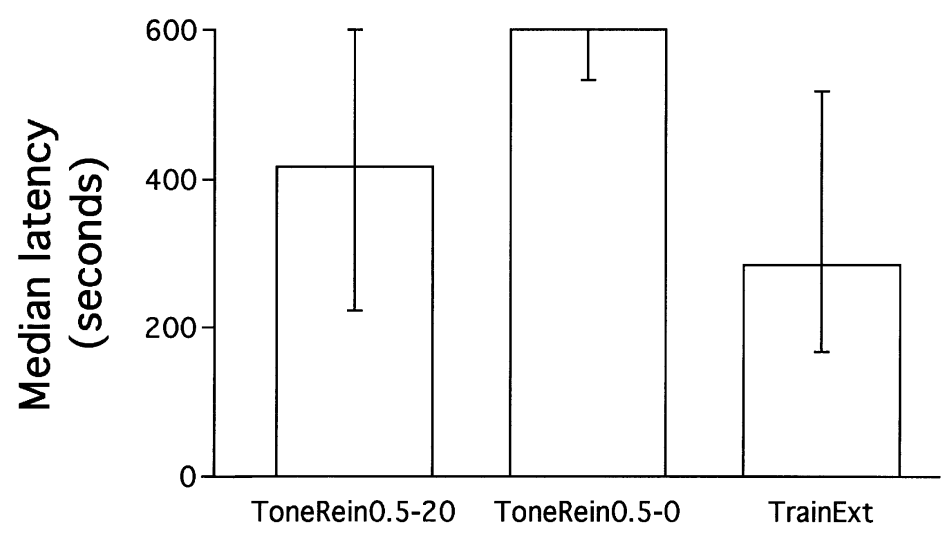

Condition

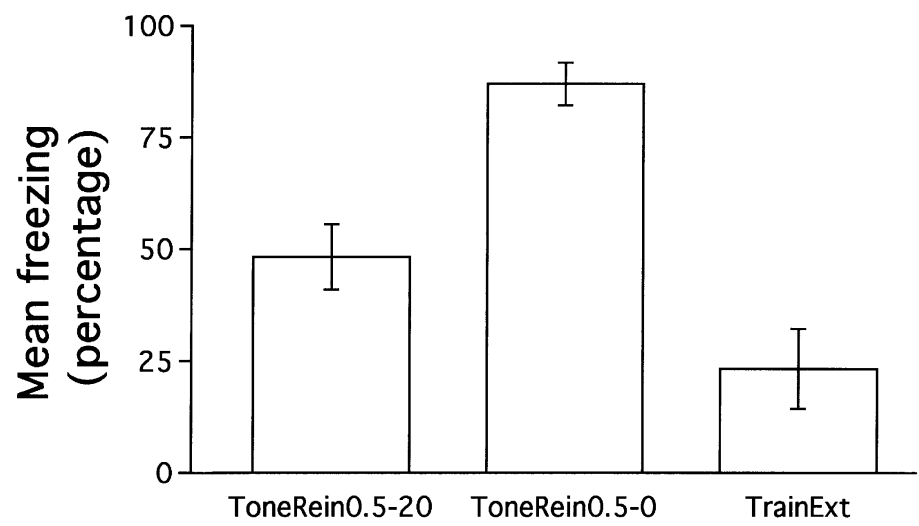

Condition

\begin{abstract}
Figure 5. Median (+ interquartile range) latency to cross into the black compartment of a black-white shuttlebox (top panel) and mean $( \pm S E M)$ percent time freezing in the reinstatement chamber (bottom panel) for rats in Experiment 5. All groups were initially trained to fear the black compartment, and this fear was subsequently extinguished in all groups. Prior to test, rats in Groups ToneRein0.5-20 and ToneRein0.5-0 were placed in the reinstatement chamber and given a single shock after a 30-sec delay; this shock was signaled by a 10-sec tone. Rats in Group ToneRein0.5-20 remained in the reinstatement chamber for 20 min after the shock, whereas rats in the other group were removed immediately after the shock.
\end{abstract}

Group TrainExt was not different from the ToneRein 0.520 group $(U=39.0)$, showing that the context extinction session attenuated the reinstatement effect.

Reinstatement context test. The mean percentage of samples in the reinstatement context scored as freezing is shown in the bottom panel of Figure 5. Rats in Group ToneRein 0.5-0 froze more when returned to the reinstatement context than subjects in either Group ToneRein0.5-20 $[F(1,26)=13.55]$ or Group TrainExt $[F(1,26)=$ $36.71]$. The levels of freezing did not differ in the latter two groups $[F(1,26)=5.97]$. These results show that an extended nonreinforced exposure to the reinstatement context was effective in reducing fear of the context, as was found in Experiments 2 and 4.

CS freezing test. The mean percentage of samples scored as freezing during the 2-min pre-CS period and the 2-min CS period is shown in Figure 6. Groups given the reinstatement shock, ToneRein 0.5-0 and ToneRein 0.520 , exhibited equivalent freezing during the pre-CS period $[F(1,26)=3.70]$, and both froze more than rats in Group TrainExt not given the reinstatement shock $[F(1,26)=13.89]$. The same pattern of results occurred during the CS period. That is, the two groups given the reinstatement treatment shock exhibited equivalent freez- 


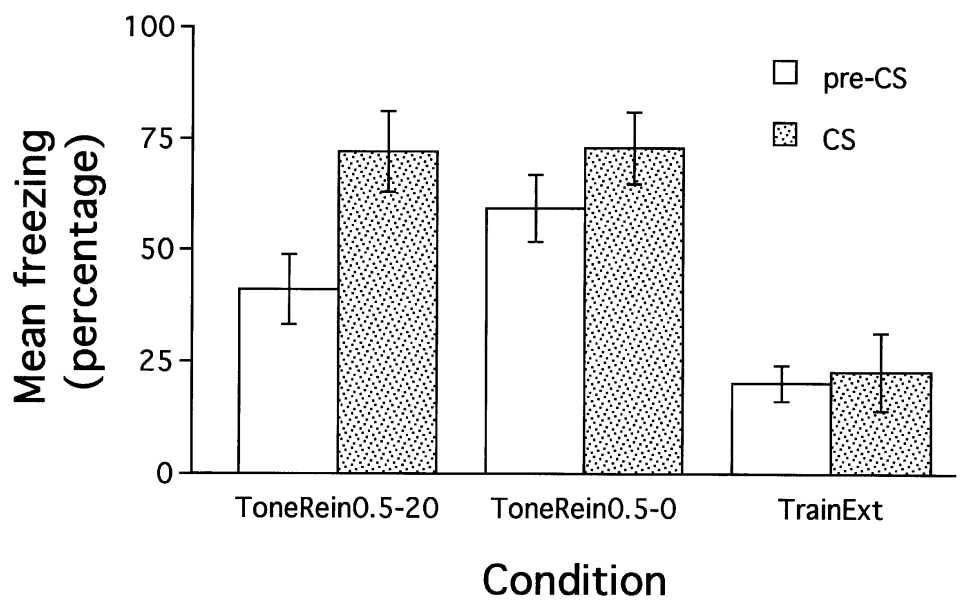

\begin{abstract}
Figure 6. Mean $( \pm S E M)$ percent time freezing during a 2-min pre-CS period and during a 2-min CS period for rats in Experiment 5. Prior to test, rats in Groups ToneRein0.5-20 and ToneRein0.5-0 were placed in the reinstatement context and given a single shock after a 30-sec delay; this shock was signaled by a 10-sec tone. Rats in Group ToneRein0.5-20 were given a 20-min nonreinforced exposure to the reinstatement context following the shock. CS, conditioned stimulus.
\end{abstract}

ing during the CS period $(F<1.0)$, and both froze more than rats not given the reinstatement treatment $[F(1,26)=$ 16.24 and 16.61]. Importantly, an interaction between group and test period was also found. That is, rats given the reinstatement shock showed an increase in freezing during the CS period relative to rats not given the reinstatement shock $[F(1,26)=9.37]$. The two reinstatement groups showed an equivalent increase in freezing during the CS period $[F(1,26)=5.21]$. The latter result shows that the two reinstatement groups were equally fearful of the CS.

The results of Experiment 5 show that rats that are fearful of a discrete $\mathrm{CS}$, but not the reinstatement context, do not exhibit reinstatement. That is, it appears that reinstatement of responding to the extinguished conditioned context (the black compartment) depends upon rats being fearful of the reinstatement context at the time of test. This result places a limitation on the new learning interpretation of reinstatement.

\section{GENERAL DISCUSSION}

The present results bear on two theoretical accounts of postextinction reinstatement: Bouton's contextual conditioning model, and Rescorla's US representation model. Both of these models can account for some, but not all, of the results of the present study. The basic features of each of these models, and the difficulties raised by the present results for each, are described below.

\section{The Contextual Conditioning Model}

Bouton and his colleagues have primarily examined postextinction reinstatement in a conditioned suppression procedure in which, after CS-US pairings, the CS is extinguished. The critical finding is that the presentation of a reinstatement shock prior to test reinstates conditioned suppression to the CS (see Bouton, 1991, 1993, for reviews). Reinstatement, according to Bouton, is due to contextual conditioning produced by the reinstatement shock. For example, in summarizing the results of several studies from his laboratory, Bouton (1991) reported a strong positive relation between contextual fear and reinstatement of responding to an extinguished CS. The reinstatement effect, according to Bouton, is not due to summation of the contextual fear with residual fear of the extinguished CS, but, rather, is a result of the context signaling retrieval of the $\mathrm{CS}-$ shock association. The results of the present study provide support for the notion that contextual conditioning is involved in postextinction reinstatement. Specifically, rats given a shock immediately after being placed in the reinstatement context did not exhibit either fear of that context or the reinstatement effect (Experiment 1). In contrast, rats shocked $30 \mathrm{sec}$ after being placed in the reinstatement context exhibited both fear of that context and the reinstatement effect (Experiments 1-5). The reinstatement effect could be attenuated in rats in this condition, however, by giving them an extended exposure $(20 \mathrm{~min}$ ) to the context after the shock (Experiments 2, 4, and 5). That is, extinction of the context fear attenuated the reinstatement effect. Bouton and Bolles (1979) also reported that extinguishing fear of the reinstatement context attenuated the reinstatement effect (see also MacArdy \& Riccio, 1995).

However, the results of the present study are problematic for Bouton's contextual conditioning model of reinstatement for at least two reasons. First, Bouton and his 
colleagues have consistently reported that reinstatement occurs only if the reinstatement shock is given in the same context as that used for test (Bouton, 1991, 1993). In contrast, in the present study the reinstatement shock was always given in a context different from that used for testing, and yet a consistent reinstatement effect was observed. As noted in the introduction, other studies have found postextinction reinstatement when the US is administered outside the test context. One might be tempted to explain this difference by suggesting that the two contexts used in the present study are so similar that rats were unable to distinguish them, whereas the contexts used by Bouton are more easily discriminated. This position is untenable, however. In the first place, the two contexts (operant chambers) used by Bouton appear to be more similar than the two contexts (the shuttlebox and the reinstatement chamber) used in the present study in terms of physical characteristics. Further, and more importantly, there is evidence that subjects were able to discriminate the two contexts used in the present study. Specifically, rats trained in the black-white shuttlebox, but not given the reinstatement shock, avoided the black compartment but did not freeze when placed in the reinstatement context, whereas rats given the reinstatement shock, but not trained in the black-white shuttlebox, froze in the former context but did not avoid the black compartment (Figures 1 and 3). Finally, rats shocked in the reinstatement context and tested in a novel black-white shuttlebox (Group Naive of Experiment 1) exhibited shorter latencies to enter the black compartment than did rats for which extinguished fear of the black compartment had been reinstated by that reinstatement shock (Experiment 1). Clearly, these two contexts are discriminable. It remains to be determined why we, but not Bouton, observed reinstatement when the US was given in a context different from the test context.

A second difficulty posed by the present results for Bouton's contextual conditioning model of reinstatement concerns the differential effects of context preexposure on reinstatement and context conditioning (Experiments 3 and 4). That is, rats given $20 \mathrm{~min}$ of exposure to the reinstatement context prior to administration of the shock exhibited a substantial reinstatement effect even though they expressed little freezing when subsequently tested in the reinstatement context. According to Bouton's model, animals exhibit reinstatement only when they are fearful of the reinstatement context. This apparent difficulty could be handled, however, by suggesting that this preexposure effect (similar to latent inhibition) involves a behaviorally silent association between the reinstatement context and shock. Although this association is not expressed in the reinstatement context, it is expressed in the black-white shuttlebox, where it signals retrieval of the black-shock association. The difficulty with this approach, however, is in specifying the exact conditions in which behaviorally silent associations are capable of signaling retrieval of a particular CS-US association. For example, extended exposure to the reinstatement context after the shock makes the context-shock association behaviorally silent but attenuates the reinstatement effect. One difference between these procedures is the order in which the memories were established. In the case where reinstatement was observed, rats received an extensive exposure to the context before the occurrence of shock, but in the case where reinstatement was not observed, rats received an extensive exposure to the context after the occurrence of shock. Perhaps the most recent memory determined what was retrieved in the subsequent passive avoidance test: In the former case, the shock memory facilitated retrieval of the conditioning memory, whereas in the latter case extinction resulted in the retrieval of the extinction memory on the subsequent passive avoidance test.

\section{The US Representation Model}

Rescorla and his colleagues also used a conditioned suppression procedure in their work on postextinction reinstatement. For example, Rescorla and Heth (1975) demonstrated that a pretest shock reinstated conditioned suppression to an extinguished CS, and Rescorla and Cunningham (1977) found the same result when a discrete stimulus (different from the original CS) signaled the shock. These investigators suggested that extinction depresses the US representation and that the pretest shock restores this representation, thus leading to increased responding at test. Although this view of extinction has been questioned (Bouton, 1991), much of the present research can be explained by this approach. Indeed, this approach easily explains what is perhaps the most perplexing finding in this study: the differential effect of context preexposure on reinstatement and context conditioning (Experiments 3 and 4). Even though context preexposure may reduce conditioning to that context, it should not alter restoration of the depressed US representation; therefore, rats in the preexposed condition would be expected to exhibit the reinstatement that was in fact observed in Experiments 3 and 4. Also consistent with this model, we observed "erasure" of reinstatement in rats given an extinction exposure to the reinstatement context after being shocked there. This finding is similar to that reported by Rescorla and Cunningham, who found that nonreinforced presentations of the CS that had been paired with the pretest reinstatement shock attenuated the reinstatement effect for the original CS. This finding was termed the "erasure" of reinstatement and was attributed to a further depression of the US representation by the extinction of the second CS. In the present study, extinction of the reinstatement context prior to test can be thought of as "erasing" reinstatement in a similar manner. However, this account would also appear to predict that the context extinction treatment would lead to a decrement in responding to the CS previously paired with that US, but that was not observed. That is, rats given the context extinction treatment exhibited the same level of freezing to the $\mathrm{CS}$ as did rats not given the context extinction treat- 
ment (Figure 6). There are at least two possible explanations for this. One is that the 2-min test period was not long enough to detect potential group differences in levels of CS-elicited freezing; if a longer test period had been used, or if multiple 2-min trials had been given, then perhaps those rats given the context extinction treatment would have exhibited less freezing to the CS than those rats not given the reinstatement context extinction treatment. A second possible explanation for the observation that both the rats given the reinstatement context extinction treatment and the rats not given the extinction treatment responded equivalently to the CS is that the status of the US representation may be more important for "ambiguous" stimuli (e.g., extinguished stimuli) than for unambiguous stimuli.

Although the US representation model accounts for much of the present results, it has difficulty with the finding that rats given an immediate shock failed to exhibit reinstatement (Experiment 1). One way to maintain this approach in the face of this finding would be to suggest that the immediate shock is not processed to the same extent as a shock given after a short delay (e.g., $30 \mathrm{sec}$ ). For instance, the simultaneous exposure to novel contextual cues and shock could have resulted in an overshadowing of the US by the context, or the novelty of the context could have diminished the impact of the shock through a novelty-induced analgesia process (Harris \& Westbrook, 1994).

In summary, this series of experiments has confirmed that extinguished fear responses to a particular context (the black compartment of a shuttlebox) can be reinstated by a shocked exposure to a different "reinstatement" context (a distinctive chamber). This reinstatement by US presentation combines with the results from other postextinction techniques (e.g., spontaneous recovery and renewal) to show that extinction masks rather than destroys the original excitatory association. One candidate for the masking observed here is a depressed US representation that was restored by the US presentation in the reinstatement context. An alternative interpretation leaves open the question of what masked the original context-shock association, but asserts that this association is activated as a consequence of the association subsequently established between the reinstatement context and shock. This series of experiments was not decisive with respect to distinguishing between these alternatives, but it did provide information about the critical parameters that determine reinstatement. Thus, it can be concluded that rats that exhibit fear responses in the reinstatement context will also show reinstatement of the original fear. However, it cannot be concluded that rats that fail to exhibit fear responses to the reinstatement context will also fail to show reinstatement of fear responses to the extinguished conditioned context.

\section{REFERENCES}

Ackil, J. K., Carman, H. M., Bakner, L., \& Riccio, D. C. (1992). Reinstatement of latent inhibition following a reminder treatment in a conditioned taste aversion paradigm. Behavioral \& Neural Biology, $\mathbf{5 8}, 232-235$.
Bevins, R. A., McPhee, J. E., Rauhut, A. S., \& Ayres, J. J. (1997). Converging evidence for one-trial context fear conditioning with an immediate shock: Importance of shock potency. Journal of Experimental Psychology: Animal Behavior Processes, 23, 312-324.

Blanchard, R. J., Fukanaga, K. K., \& Blanchard, D. C. (1976). Environmental control of defensive reactions to footshock. Bulletin of the Psychonomic Society, 8, 129-130.

Bouton, M. E. (1984). Differential control by context in the inflation and reinstatement paradigms. Journal of Experimental Psychology: Animal Behavior Processes, 10, 56-74.

Bouton, M. E. (1988). Context and ambiguity in the extinction of emotional learning: Implications for exposure therapy. Behaviour Research \& Therapy, 26, 137-149.

Bouton, M. E. (1991). Context and retrieval in extinction and in other examples of interference in simple associative learning. In L. Dachowski \& C. F. Flaherty (Eds.), Current topics in animal learning: Brain, emotion, and cognition (pp. 25-53). Hillsdale, NJ: Erlbaum.

Bouton, M. E. (1993). Context, time, and memory retrieval in the interference paradigms of Pavlovian learning. Psychological Bulletin, 114, 80-99.

Bouton, M. E. (1994). Conditioning, remembering and forgetting. Journal of Experimental Psychology: Animal Behavior Processes, 20, 219-231.

Bouton, M. E., \& Bolles, R. C. (1979). Role of conditioned contextual stimuli in reinstatement of extinguished fear. Journal of Experimental Psychology: Animal Behavior Processes, 5, 368-378.

Bouton, M. E., \& Bolles, R. C. (1985). Contexts, event memories, and extinction. In P. D. Balsam \& A. Tomie (Eds.), Context and learning (pp. 133-166). Hillsdale, NJ: Erlbaum.

Bouton, M. E., \& King, D. A. (1983). Contextual control of the extinction of conditioned fear: Tests for the associative value of the context. Journal of Experimental Psychology: Animal Behavior Processes, 12, 4-15.

Bouton, M. E., \& Ricker, S. T. (1994). Renewal of extinguished responding in a second context. Animal Learning \& Behavior, 22, 317324

FANSELOW, M. S. (1980). Conditional and unconditional components of post-shock freezing. Pavlovian Journal of Biological Sciences, 15, 177-182.

FANSELOW, M. S. (1986). Associative vs topographical accounts for the immediate-shock freezing deficit in rats: Implications for the response selection rules governing species-specific defensive reactions. Learning \& Motivation, 17, 16-39.

FANSELOW, M. S. (1990). Factors governing one-trial contextual conditioning. Animal Learning \& Behavior, 18, 264-270.

Harris, J. A., \& WestBRoOK, R. F. (1994). Effects of midazolam and naloxone in rats tested for sensitivity/reactivity to formalin pain in a familiar, novel or aversively conditioned environment. Psychopharmacology, 115, 65-72.

Kasprow, W. J., Schachtman, T. R., Cacheiro, H., \& Miller, R. R. (1984). Extinction does not depend upon degredation of event memories. Bulletin of the Psychonomic Society, 22, 95-98.

Kiernan, M. J., \& WestbrooK, R. F. (1993). Effects of exposure to a to-be-shocked environment upon the rat's freezing response: Evidence for facilitation, latent inhibition, and perceptual learning. Quarterly Journal of Experimental Psychology, 46B, 271-288.

Kiernan, M. J., Westbrook, R. F., \& Cranney, J. (1995). Immediate shock, passive avoidance, and potentiated startle: Implications for the unconditioned response to shock. Animal Learning \& Behavior, 23, 22-30.

Killcross, A. S., Kiernan, M. J., Dwyer, D., \& Westbrook, R. F. (1998). Loss of latent inhibition of contextual conditioning following nonreinforced context exposure in rats. Quarterly Journal of Experimental Psychology, 51B, 75-90.

KonORSKI, J. (1948). Conditioned reflexes and neuron organization. Cambridge: Cambridge University Press.

Kraemer, P. J., \& Roberts, W. A. (1984). The influence of flavor preexposure and test interval on conditioned taste aversions in the rat. Learning \& Motivation, 15, 259-278.

Lashley, R. L., Richardson, R., \& Riccio, D. C. (1987). ACTH- and noncontingent footshock-induced recovery of an extinguished passive avoidance response. Physiology \& Behavior, 40, 677-680. 
MacArdy, E. A., \& Riccio, D. C. (1995). Time-dependent changes in the effectiveness of a noncontingent footshock reminder. Learning \& Motivation, 26, 29-42.

Mackintosh, N. J. (1975). A theory of attention: Variations in the associability of stimuli with reinforcement. Psychological Review, 82, 276-298.

Pavlov, I. P. (1927). Conditioned reflexes (G. V. Anrep, Trans.). London: Oxford University Press.

Pearce, J. M., \& Hall, G. (1980). A model for Pavlovian learning: Variations in the effectiveness of conditioned but not unconditioned stimuli. Psychological Review, 87, 532-552.

Rescorla, R. A. (1979). Conditioned inhibition and extinction. In A. Dickinson \& R. A. Boakes (Eds.), Mechanisms of learning and motivation (pp. 83-110). Hillsdale, NJ: Erlbaum.

Rescorla, R. A., \& Cunningham, C. L. (1977). The erasure of reinstated fear. Animal Learning \& Behavior, 5, 386-394.

RescoRla, R. A., \& HeTh, C. D. (1975). Reinstatement of fear to an ex- tinguished conditioned stimulus. Journal of Experimental Psychology: Animal Behavior Processes, 104, 88-96.

Rescorla, R. A., \& WAgner, A. R. (1972). A theory of pavlovian conditioning: Variations in the effectiveness of reinforcement and nonreinforcement. In A. H. Black \& W. F. Prokasy (Eds.), Classical conditioning II: Current research and theory (pp. 64-99). New York: Appleton-Century-Croft.

Schachtman, T. R., Brown, A. M., \& Miller, R. R. (1985). Reinstatement-induced recovery of a taste- $\mathrm{LiCl}$ association following extinction. Animal Learning \& Behavior, 13, 223-227.

Westbrook, R. F., Good, A. J., \& Kiernan, M. J. (1994). Effects of the interval between exposure to a novel environment and the occurrence of shock on the freezing responses of rats. Quarterly Journal of Experimental Psychology, 47B, 427-446.

(Manuscript received March 31, 1998; revision accepted for publication May 27, 1998.) 